\title{
Association of thyroid nodules with adiposity: a community-based cross- sectional study in China
}

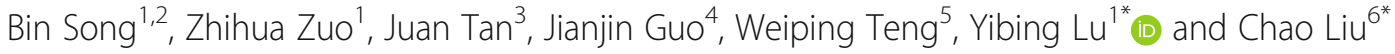

\begin{abstract}
Background: The association between thyroid nodules and adiposity remains controversial. We performed a crosssectional, community-based study to examine whether thyroid nodules are associated with overweight and obesity, as defined with body mass index (BMI) and waist circumference.

Methods: The study included 1482 subjects ( $\geq 20$ years of age; residing in Nanjing, China) receiving questionnaire interview, anthropometric measurements, laboratory tests and thyroid ultrasonography in 2009-2010. Overweight and obesity were defined as BMI $\geq 24$ and $\geq 28 \mathrm{~kg} / \mathrm{m}^{2}$, respectively. Central obesity was defined as waist circumference at $\geq 90 \mathrm{~cm}$ in men and $\geq 80 \mathrm{~cm}$ in women. A sensitivity analysis was conducted using the American Diabetes Association (ADA) criteria for overweight and obesity (BMI $\geq 23$ and $\geq 25 \mathrm{~kg} / \mathrm{m}^{2}$ ).

Results: Thyroid nodules were identified in $12.6 \%$ of the subjects. A greater proportion of the subjects with thyroid nodules had a BMl at $\geq 24 \mathrm{~kg} / \mathrm{m}^{2}$ (51.9\% vs. $40.5 \%$ in those without thyroid nodules, $P=0.003$ ) and central obesity (43. $3 \%$ vs. $24.2 \%, P<0.001)$. After adjustment for other confounders, central obesity was still associated with significantly elevated risk of thyroid nodules (OR 1.62,95\%Cl 1.14-2.28), whereas obesity/overweight based on BMI was not in both the main analysis and sensitivity analysis with the alternative criteria. In the subgroup analysis, BMl $\geq 24 \mathrm{~kg} / \mathrm{m}^{2}(\mathrm{OR} 1.61$, $95 \% \mathrm{Cl} 1.01-2.54$ ), as well as $\mathrm{BMI} \geq 25 \mathrm{~kg} / \mathrm{m}^{2}$ (OR $\left.1.95,95 \% \mathrm{Cl} 1.14-3.34\right)$, was significantly associated with higher risk of thyroid nodules among women. Using the ADA criteria, overweight and obesity were associated with thyroid nodules (OR 5.59, 95\%Cl 1.39-22.51 and 5.15, 95\%Cl 1.30-20.37) in thyroid-stimulating hormone (TSH) > 4.2 mlU/L subgroup. Central obesity correlated with higher risk of thyroid nodules regardless of age $(<50$ years: OR $1.87,95 \% \mathrm{Cl} 1.05-3.32$ : $\geq 50$ years: OR 1.54, 95\%Cl 1.00-2.37) and in the following subgroups: men (OR 1.91,95\%Cl 1.14-3.20), TSH > 4.2 mlU/L (OR 3.05, 95\%Cl 1.01-9.22), and urine iodine $\geq 200 \mu \mathrm{g} / \mathrm{L}$ (OR 1.79, 95\%Cl 1.14-2.81).
\end{abstract}

Conclusion: Waist circumference is superior to BMl for assessing risk of thyroid nodules in Chinese subjects.

Keywords: Thyroid nodules, Body mass index, Overweight, Waist circumference, Central obesity

\section{Background}

Thyroid nodules are one of the most common thyroid diseases and their incidence has been rising in recent decades worldwide. Although most thyroid nodules are benign, detecting them early is important because there is always risk that the nodules may be cancerous [1].

\footnotetext{
*Correspondence: luyibing2003@163.com; liuchao@nfmcn.com 'Department of Endocrinology, The Second Affiliated Hospital of Nanjing Medical University, 125 Jiangjiayuan Road, Nanjing 211166, China

${ }^{6}$ Endocrine and Diabetes Center, Affiliated Hospital of Integrated Traditional Chinese and Western Medicine, Nanjing University of Chinese Medicine, 8 Huadian East Road, Nanjing 210028, China

Full list of author information is available at the end of the article
}

Several factors have been associated with the formation of thyroid nodules, including gender [2-4], age [2-9], thyroid-stimulating hormone (TSH) [9], and iodine intake $[10,11]$. Numerous studies have also associated thyroid nodules with adiposity [3-5, 8, 9, 12-14], which is traditionally evaluated based on body mass index (BMI). While some studies have supported a positive correlation between BMI and risk of thyroid nodules [3, $5,13]$, particularly in women, other studies have failed to detect this association $[2,6,7]$, including our own work with children [15]. In addition, two case-control studies from different countries found that morbid obesity in 
women (BMI $\geq 40 \mathrm{~kg} / \mathrm{m}^{2}$ ) was associated with lower prevalence of thyroid nodules [12, 14]. These findings call into question whether BMI is useful as a predictor of thyroid nodule risk.

Another measure of adiposity is waist circumference. While BMI cannot distinguish between general adiposity and central (or abdominal) obesity, waist circumference reflects specifically central obesity. In several types of chronic diseases, including cardiovascular disease [16], renal disease [17] and metabolic syndrome [18], central obesity correlates more strongly with adverse health outcomes than higher BMI. Several studies have associated metabolic syndrome with increased prevalence of thyroid nodules [2, 4, 8, 9, 19], and one of these studies found waist circumference to correlate positively with thyroid nodules in men, although not in women [9].

Whether central obesity is associated with thyroid nodules is unclear. Studies from our group [4] and others [8] involving individuals showing moderate iodine intake have linked central obesity to higher prevalence of thyroid nodules, whereas another study of individuals with mild to moderate iodine deficiency failed to find this association after adjusting for insulin resistance [19]. These discrepancies may reflect differences in study design, sample size, ethnicity, gender and iodine levels.

Therefore we undertook the present study to clarify whether central obesity is significantly associated with the presence of thyroid nodules and may therefore serve as a useful indicator of thyroid nodule risk. In addition, we compared the association of thyroid nodule risk with higher waist circumference or elevated BMI in order to determine whether one of these adiposity indicators is superior to the other. Our study population came from our previous study designed to investigate thyroid diseases and iodine nutrition in a Chinese communitybased population. Median urinary iodine concentration in this population was $239 \mu \mathrm{g} / \mathrm{L}$, indicating more than adequate iodine intake [11].

\section{Methods}

\section{Subjects}

Participants in the present study were taken from the population analyzed in our multicenter, cross-sectional epidemiological investigation of thyroid diseases in 10 Chinese cities [11]. From among this population originally recruited in 2009-2010, we selected a community in Nanjing where most inhabitants had lived for more than 5 years. To avoid recruitment bias, we screened the residents based on their household registrations and stratified sampling by age to mirror the average age composition of Chinese urban populations, based on 2008 data from the Chinese National Bureau of Statistics. This led us to enroll 1572 individuals older than 20 years old (men: women, 1:1.2), who showed the following age distribution: 20-
29 years, $17.5 \%$; $30-39$ years, $23.2 \%$; $40-49$ years, $23.3 \%$; 50-59 years, $17.9 \%$; $60-69$ years, $10.1 \%$; $\geq 70$ years, $7.9 \%$.

Participants were excluded if they were pregnant women or women who had given birth during the preceding year; if they had adrenocortical insufficiency, renal insufficiency or other serious systemic disease; or if they were receiving any treatment that might affect thyroid function and iodine excretion, such as glucocorticoids, antiepileptic drugs, amiodarone or iodine-containing contrast agents. Details of the study design, eligibility, recruitment, survey procedures and participant characteristics were reported elsewhere $[11,20]$. This study was conducted in accordance with the Declaration of Helsinki and approved by the medical ethics committee of China Medical University (serial number: IRB [2008]34) [11]. Written informed consent was obtained from all participants before any sample or data collection.

\section{Data collection}

As previously described [11], a structured questionnaire was administered by trained staff during a face-to-face interview in order to collect data on demographic characteristics, smoking status, dietary habits, type of salt used, and personal or family history of thyroid disease. Physical examination included weight (measured to nearest $0.5 \mathrm{~kg}$ ), height (nearest $0.1 \mathrm{~cm}$ ), waist circumference (nearest $0.1 \mathrm{~cm}$ ) and blood pressure (nearest $1 \mathrm{mmHg}$ ). Height and weight were evaluated using a calibrated balance beam scale when subjects wore light clothes and were barefoot. Waist circumference was measured midway between the lowest rib and iliac crest using a tape measure while participants were standing and breathing normally. Systolic and diastolic blood pressure was measured using a standard manual mercury sphygmomanometer while the subject was seated. Pressure was measured twice at an interval of $30 \mathrm{~s}$, and the readings were averaged. Overnight fasting blood and urine samples from all subjects were assayed for serum levels of TSH, thyroid peroxidase antibodies (TPOAb), thyroglobulin antibodies (TgAb) and urine iodine concentration (UIC). Normal reference ranges were $0.27-4.2 \mathrm{mIU} / \mathrm{L}$ for $\mathrm{TSH}, 0-34 \mathrm{IU} / \mathrm{L}$ for TPOAb and 0-115 IU/L for TgAb [11]. Thyroid ultrasonography was performed by professional physicians who had received centralized training using a portable instrument (LOGIQ a50, 7.5 MHz; GE Healthcare).

\section{Definition of variables}

A thyroid nodule was defined as a discrete lesion that was distinct from the surrounding thyroid parenchyma and that had a solid portion, regardless of whether a cystic portion was present [21]. Central obesity was defined as waist circumference $\geq 90 \mathrm{~cm}$ for men or $\geq 80 \mathrm{~cm}$ for women, based on the criteria recommended for Chinese adults by the International Diabetes Federation [22]. BMI 
was calculated as weight $(\mathrm{kg})$ divided by height $(\mathrm{m})$ squared, and definition of overweight and obesity was BMI $\geq 24$ and $\geq 28 \mathrm{~kg} / \mathrm{m}^{2}$, respectively, according to the 2016 China consensus statement on management of overweight/obesity [23]. Additionally, a sensitivity analysis was conducted using the American Diabetes Association definition for overweight $\left(\geq 23 \mathrm{~kg} / \mathrm{m}^{2}\right)$ and obesity ( $\geq 25 \mathrm{~kg} /$ $\mathrm{m}^{2}$ ) for Asians [24]. Elevated TSH was defined as $>4.2$ $\mathrm{mIU} / \mathrm{L}$, and the presence of antithyroid antibodies was defined as TPOAb $>34 \mathrm{IU} / \mathrm{L}$ or TgAb $>115 \mathrm{IU} / \mathrm{L}$. UIC was classified as low if $<200 \mu \mathrm{g} / \mathrm{L}$ and high if $\geq 200 \mu \mathrm{g} / \mathrm{L}$ based on World Health Organization guidelines.

\section{Statistical analysis}

Continuous data are reported as mean \pm standard deviation (SD) or median (interquartile range), while categorical data are reported as count and percentage. Differences in means, medians or proportions between individuals with or without thyroid nodules were assessed for significance using the Mann-Whitney $\mathrm{U}$ and chi-squared tests. Logistic regression was used to calculate odds ratios (ORs) and 95\% confidence intervals $(95 \% \mathrm{CIs})$ to assess the association of thyroid nodules with waist circumference or BMI. Adjusted logistic regression models took into account age, gender, education, profession, smoking status, systolic and diastolic blood pressure, TSH and UIC.

Subgroup analyses were performed by treating BMI and waist circumference as categorical variables and stratifying subjects based on four potential risk factors for thyroid nodules: gender, age $(<50$ or $\geq 50$ years), TSH ( $\leq 4.2$ or $>$ $4.2 \mathrm{mIU} / \mathrm{L})$, and UIC $(<200$ or $\geq 200 \mu \mathrm{g} / \mathrm{L})$. Heterogeneity in the influence of BMI or waist circumference on thyroid nodules between participants with or without these factors was evaluated by adding an interaction term to the relevant adjusted model. All analyses were performed using EmpowerStats (http://www.empowerstats.com; X\&Y Solutions, Boston, MA). A two-sided significance level of 0.05 was used to evaluate statistical significance.

\section{Results}

\section{Baseline characteristics}

Of the 1572 individuals recruited, 40 were excluded from the study because they did not complete the survey, resulting in a response rate of $97.4 \%$. We excluded another 50 participants because of previous thyroid disease. In the end, 1482 subjects were included in the study (mean age, $44.5 \pm 15.4$ years), of whom $682(46.0 \%)$ were males and $187(12.6 \%)$ had thyroid nodules (Table 1). Mean BMI was $23.52 \pm 3.33 \mathrm{~kg} / \mathrm{m}^{2}$ and mean waist circumference was $79.68 \pm 9.56 \mathrm{~cm} ; 41.9 \%$ of subjects had BMI $\geq 24 \mathrm{~kg} / \mathrm{m}^{2}$, and $26.7 \%$ had central obesity based on waist circumference. Individuals with thyroid nodules were significantly older than those without nodules (54.6 vs. 43.0 years, $P<0.001$ ) and had significantly higher BMI
(24.10 vs. $\left.23.44 \mathrm{~kg} / \mathrm{m}^{2}, P=0.011\right)$ and waist circumference (82.38 vs. $79.29 \mathrm{~cm}, P=0.030)$, as well as significantly lower TSH ( 2.17 vs. $2.52 \mathrm{mIU} / \mathrm{L}, P<0.001)$. The proportion of individuals with $B M I \geq 24 \mathrm{~kg} / \mathrm{m}^{2}$ was significantly higher among individuals with nodules $(51.9 \%$ vs. $40.5 \%$, $P=0.003)$, as was the proportion of individuals with central obesity $(43.3 \%$ vs. $24.2 \%, P<0.001)$. Individuals with or without thyroid nodules were similar in terms of gender composition, UIC, smoking status, family history of thyroid disease, iodized salt intake, seafood intake, and TPOAb or TgAb positivity.

\section{Associations of thyroid nodules with waist circumference and BMI}

Associations of BMI and waist circumference with thyroid nodules across the entire study population are shown in Table 2. BMI considered as a continuous variable (per $1 \mathrm{~kg} / \mathrm{m}^{2}$ increase) was associated with increased risk of thyroid nodules in the unadjusted model (OR 1.06, 95\% CI 1.01-1.11), but this association was no longer significant after adjusting for age, gender, education, profession, smoking status, systolic and diastolic pressure, TSH and UIC (OR 1.02, 95\%CI 0.97-1.07). BMI as a categorical variable was also associated with elevated risk of thyroid nodules: the OR for individuals with BMI $\geq 24 \mathrm{~kg} / \mathrm{m}^{2}$ relative to those with $\mathrm{BMI}<24 \mathrm{~kg} / \mathrm{m}^{2}$ was $1.59(95 \% \mathrm{CI}$ $1.17-2.16)$ in the unadjusted model. Again, this association was not significant in the adjusted model (OR 1.33, 95\% CI 0.95-1.86). Additionally, using the ADA definition for overweight $\left(\geq 23 \mathrm{~kg} / \mathrm{m}^{2}\right)$ and obesity $\left(\geq 25 \mathrm{~kg} / \mathrm{m}^{2}\right)$ for Asians, results are consistent and shown in Additional file 1: Table S1. In the unadjusted model, the ORs for individuals with BMI $\geq 23,<25 \mathrm{~kg} / \mathrm{m}^{2}$ and BMI $\geq 25 \mathrm{~kg} / \mathrm{m}^{2}$ relative to those with BMI $<23 \mathrm{~kg} / \mathrm{m}^{2}$ were $1.62(95 \% \mathrm{CI} 1.10-2.40)$ and $1.70(95 \% \mathrm{CI} 1.19-2.44)$, respectively. Those associations were not significant in the adjusted model (OR 1.47, 95\%CI 0.97-2.23 and OR 1.43, 95\%CI 0.96-2.13, respectively).

Waist circumference considered as a continuous variable (per $1 \mathrm{~cm}$ increase) was significantly associated with increased risk of thyroid nodules in an unadjusted model (OR 1.03, 95\%CI 1.02-1.05) as well as in the adjusted model (OR 1.02, 95\%CI 1.00-1.04). Central obesity, defined according to a gender-specific waist circumference cut-off, was significantly associated with higher risk of thyroid nodules in the unadjusted model (OR 2.39, 95\%CI 1.74-3.27) and adjusted model (OR 1.62, 95\%CI 1.14-2.28).

\section{Subgroup analyses based on gender, age, TSH and UIC}

Possible relationships of thyroid nodules with BMI or waist circumference, both considered as categorical variables, were explored in different subgroups of study participants (Table 3 ). BMI $\geq 24 \mathrm{~kg} / \mathrm{m}^{2}$ was significantly associated with higher thyroid nodule risk only in 
Table 1 Baseline characteristics of a community-based Chinese population with or without thyroid nodules

\begin{tabular}{|c|c|c|c|c|}
\hline Characteristic & $\begin{array}{l}\text { Total } \\
(n=1482)\end{array}$ & $\begin{array}{l}\text { No nodules } \\
(n=1295)\end{array}$ & $\begin{array}{l}\text { Nodules } \\
(n=187)\end{array}$ & $P$ \\
\hline Male & $682(46.0)$ & $605(46.7)$ & $77(41.2)$ & 0.155 \\
\hline Age (years) & $44.5 \pm 15.4$ & $43.0 \pm 14.8$ & $54.6 \pm 15.3$ & $<0.001$ \\
\hline BMI $\left(\mathrm{kg} / \mathrm{m}^{2}\right)$ & $23.52 \pm 3.33$ & $23.44 \pm 3.35$ & $24.10 \pm 3.18$ & 0.011 \\
\hline WC $(\mathrm{cm})$ & $79.68 \pm 9.56$ & $79.29 \pm 9.53$ & $82.38 \pm 9.36$ & $<0.001$ \\
\hline SBP $(\mathrm{mmHg})$ & $123.22 \pm 16.83$ & $122.38 \pm 16.43$ & $129.06 \pm 18.38$ & $<0.001$ \\
\hline $\mathrm{DBP}(\mathrm{mmHg})$ & $78.42 \pm 10.74$ & $78.11 \pm 10.70$ & $80.55 \pm 10.76$ & 0.004 \\
\hline UIC ( $\mu \mathrm{g} / \mathrm{L})$ & $240.6(163.6-336.5)$ & $243.0(165.2-338.1)$ & 222.0 (151.6-328.6) & 0.193 \\
\hline TSH (mIU/L) & $2.48(1.67-3.46)$ & $2.52(1.71-3.45)$ & $2.17(1.44-3.59)$ & 0.030 \\
\hline Education & & & & $<0.001$ \\
\hline Primary school or illiterate & $132(8.9)$ & $106(8.2)$ & $26(13.9)$ & \\
\hline Junior high school & $399(26.9)$ & $334(25.8)$ & $65(34.8)$ & \\
\hline Senior high school & $697(47.0)$ & $627(48.4)$ & $70(37.4)$ & \\
\hline Undergraduate or above & $254(17.1)$ & $228(17.6)$ & $26(13.9)$ & \\
\hline Profession & & & & $<0.001$ \\
\hline Employed & $1045(70.5)$ & $947(73.1)$ & $98(52.4)$ & \\
\hline Unemployed & $354(23.9)$ & $271(20.9)$ & $83(44.4)$ & \\
\hline Not reported & $83(5.6)$ & $77(5.9)$ & $6(3.2)$ & \\
\hline Smoking status & & & & 0.187 \\
\hline Never & $1084(73.1)$ & $937(72.4)$ & $147(78.6)$ & \\
\hline Currently & $386(26.0)$ & $347(26.8)$ & $39(20.9)$ & \\
\hline Formerly & $12(0.8)$ & $11(0.8)$ & $1(0.5)$ & \\
\hline Family history of thyroid disease & $43(2.9)$ & $35(2.7)$ & $8(4.3)$ & 0.241 \\
\hline lodized salt & $1450(97.8)$ & $1266(97.8)$ & $184(98.4)$ & 0.789 \\
\hline Seafood intake & & & & 0.851 \\
\hline Never & $83(5.6)$ & $73(5.6)$ & $10(5.3)$ & \\
\hline Occasionally & $1166(78.7)$ & $1021(78.8)$ & $145(77.5)$ & \\
\hline Frequently & $233(15.7)$ & $201(15.5)$ & $32(17.1)$ & \\
\hline TPOAb positive & $139(9.4)$ & $122(9.4)$ & $17(9.1)$ & 0.885 \\
\hline TgAb positive & $163(11.9)$ & $141(10.9)$ & $22(11.8)$ & 0.720 \\
\hline $\mathrm{BMI} \geq 24 \mathrm{~kg} / \mathrm{m}^{2}$ & $621(41.9)$ & $524(40.5)$ & $97(51.9)$ & 0.003 \\
\hline Central obesity & $395(26.7)$ & $314(24.2)$ & $81(43.3)$ & $<0.001$ \\
\hline
\end{tabular}

Continuous data are shown as the mean \pm standard deviation or median (interquartile), and categorical data as $n(\%)$

Table 2 Analysis of associations of thyroid nodules with BMI and waist circumference

\begin{tabular}{|c|c|c|c|c|}
\hline Predictor & Unadjusted OR, 95\%Cl & $P$ & ${ }^{a}$ Adjusted OR, 95\%Cl & $P$ \\
\hline BMI (per $\left.\mathrm{kg} / \mathrm{m}^{2}\right)$ & $1.06(1.01,1.11)$ & 0.011 & $1.02(0.97,1.07)$ & 0.459 \\
\hline \multicolumn{5}{|l|}{ BMl } \\
\hline$<24 \mathrm{~kg} / \mathrm{m}^{2}$ & Ref & & Ref & \\
\hline$\geq 24 \mathrm{~kg} / \mathrm{m}^{2}$ & $1.59(1.17,2.16)$ & 0.003 & $1.33(0.95,1.86)$ & 0.100 \\
\hline Waist circumference (per cm) & $1.03(1.02,1.05)$ & $<0.001$ & $1.02(1.00,1.04)$ & 0.034 \\
\hline \multicolumn{5}{|l|}{ Central obesity } \\
\hline No & Ref & & Ref & \\
\hline Yes & $2.39(1.74,3.27)$ & $<0.001$ & $1.62(1.14,2.28)$ & 0.007 \\
\hline
\end{tabular}

${ }^{a}$ The adjusted OR controls for age, gender, education, profession, smoking status, systolic and diastolic blood pressure, TSH, and UIC 
Table 3 Associations of thyroid nodules with BMl and waist circumference in subgroups of subjects stratified by gender, age, TSH or UIC

\begin{tabular}{|c|c|c|c|c|c|c|c|}
\hline \multirow[t]{2}{*}{ Predictor } & \multirow[b]{2}{*}{$N$} & \multicolumn{3}{|l|}{$\mathrm{BMI} \geq 24 \mathrm{~kg} / \mathrm{m}^{2}$} & \multicolumn{3}{|l|}{ Central obesity } \\
\hline & & Adjusted OR, 95\%Cl & $P$ & $P$ interaction & Adjusted OR, 95\%Cl & $P$ & $P$ interaction \\
\hline \multicolumn{8}{|l|}{ Gender $^{a}$} \\
\hline Male & 682 & $1.14(0.68,1.90)$ & 0.626 & 0.372 & $1.91(1.14,3.20)$ & 0.013 & 0.272 \\
\hline Female & 800 & $1.61(1.01,2.54)$ & 0.044 & & $1.44(0.89,2.35)$ & 0.142 & \\
\hline \multicolumn{8}{|l|}{$\operatorname{Age}^{\mathrm{b}}$} \\
\hline$<50$ years & 958 & $1.61(0.94,2.74)$ & 0.081 & 0.185 & $1.87(1.05,3.32)$ & 0.033 & 0.632 \\
\hline$\geq 50$ years & 524 & $1.14(0.74,1.75)$ & 0.559 & & $1.54(1.00,2.37)$ & 0.048 & \\
\hline \multicolumn{8}{|l|}{$\mathrm{TSH}^{c}$} \\
\hline$\leq 4.2 \mathrm{mlU} / \mathrm{L}$ & 1259 & $1.17(0.81,1.68)$ & 0.408 & 0.161 & $1.41(0.97,2.05)$ & 0.069 & 0.194 \\
\hline$>4.2 \mathrm{mlU} / \mathrm{L}$ & 223 & $2.52(0.91,6.99)$ & 0.076 & & $3.05(1.01,9.22)$ & 0.048 & \\
\hline \multicolumn{8}{|l|}{$U I^{d}$} \\
\hline$<200 \mu \mathrm{g} / \mathrm{L}$ & 543 & $1.08(0.63,1.85)$ & 0.785 & 0.375 & $1.30(0.75,2.24)$ & 0.351 & 0.373 \\
\hline$\geq 200 \mu \mathrm{g} / \mathrm{L}$ & 939 & $1.48(0.95,2.29)$ & 0.082 & & $1.79(1.14,2.81)$ & 0.012 & \\
\hline
\end{tabular}

${ }^{a}$ Adjusted for age, education, profession, smoking status, systolic and diastolic blood pressure, TSH, and UIC

badjusted for gender, education, profession, smoking status, systolic and diastolic blood pressure, TSH, and UIC

cadjusted for age, gender, education, profession, smoking status, systolic and diastolic blood pressure, and UIC

${ }^{d}$ adjusted for age, gender, education, profession, smoking status, systolic and diastolic blood pressure, and TSH

women (OR 1.61, 95\%CI 1.01-2.54), while central obesity significantly correlated with increased risk of thyroid nodules in men (OR 1.91, 95\%CI 1.14-3.20), individuals younger than 50 years (OR 1.87, 95\% CI 1.05-3.32), individuals at least 50 years (OR 1.54, 95\% CI 1.00-2.37), individuals with $\mathrm{TSH}>4.2 \mathrm{mIU} / \mathrm{L}$ (OR $3.05,95 \% \mathrm{CI}$ $1.01-9.22$ ) and UIC $\geq 200 \mu \mathrm{g} / \mathrm{L}$ (OR $1.79,95 \% \mathrm{CI}, 1.14-$ 2.81 ). Neither $B M I \geq 24 \mathrm{~kg} / \mathrm{m}^{2}$ nor central obesity interacted significantly with any of the four potential thyroid nodule risk factors of gender, age, TSH, or UIC (all $P$ for interaction $>0.05$ ).

Additionally, in the sensitivity analysis according to ADA definition for Asians (Additional file 2: Table S2), compared with $\mathrm{BMI}<23 \mathrm{~kg} / \mathrm{m}^{2}, \mathrm{BMI} \geq 25 \mathrm{~kg} / \mathrm{m}^{2}$ was significantly associated with higher thyroid nodule risk among women (OR 1.95, 95\%CI 1.14-3.34) and individuals with TSH $>4.2 \mathrm{mIU} / \mathrm{L}$ (OR 5.15, 95\%CI 1.3020.37). Similarly, individuals with BMI $\geq 23,<25 \mathrm{~kg} / \mathrm{m}^{2}$ relative to those with BMI $<23 \mathrm{~kg} / \mathrm{m}^{2}$ was $5.59(95 \% \mathrm{CI}$ 1.39-22.51) in TSH $>4.2 \mathrm{mIU} / \mathrm{L}$ subgroup. Interestingly, BMI based on 23 and $25 \mathrm{~kg} / \mathrm{m}^{2}$ interacted significantly with TSH $(P$ for interaction $=0.044)$.

\section{Discussion}

In this cross-sectional study of a community-based population in China showing more than adequate iodine intake, we were unable to confirm a significant association between high BMI and risk of thyroid nodules, except for the subgroup of women. In contrast, we found an independent, positive correlation between waist circumference - treated as a categorical or continuous variable - and risk of thyroid nodules. Participants with central obesity were at 1.62 -fold higher risk of thyroid nodules than those with normal waist circumference, and this relationship was also observed in nearly all subgroup analyses. Our findings suggest that in Chinese individuals with more than adequate iodine intake, higher waist circumference is more strongly associated than higher BMI with elevated risk of thyroid nodules. This may mean that adipose tissue in the waist area may influence risk of thyroid nodules differently from adipose tissue elsewhere in the body.

Previous studies in different populations have reached conflicting conclusions about the association between BMI and risk of thyroid nodules. Two community-based studies in China reported that overweight and general obesity (as measured using BMI) were associated with higher risk of thyroid nodules only in women $[5,13]$, and we found the same result in our population when we treated BMI as a categorical variable. However, another Chinese study did not detect this association, perhaps because of insufficient sample size [2]. A previous community-based study in China found that BMI defined as a continuous variable correlated positively with risk of thyroid nodules [3], but two other studies involving healthy individuals undergoing physical exams failed to detect this association [6, 7], similar to our negative result in the present study. To make things more complicated, two studies outside Asia reported a negative relationship between BMI and risk of thyroid nodules [12, 14]. In light of the literature, we speculate that BMI may not correlate linearly with thyroid nodule risk, and so it may be unsuitable for assessing the influence of adiposity on the presence of thyroid nodules. Whether this is true only for Chinese populations or more broadly requires further study. 
The poor performance of BMI as an indicator of thyroid nodules may relate to the fact that it is a quite nonspecific measure of adiposity, aggregating measures of muscle mass, peripheral and abdominal adipose tissue, and bone mass [17]. Waist circumference, in contrast, specifically reflects abdominal adipose distribution, which mainly consists of subcutaneous and visceral adipose tissue [25, 26]. This specificity may help to explain why waist circumference appears to be a better indicator of thyroid nodule risk. Central obesity has already been linked to greater likelihood of adverse metabolic health conditions [18, 27], including hyperglycemia, hypertension and dyslipidemia, which reflect a cluster of components in metabolic syndrome. Only approximately 20\% of obese individuals (based on BMI) have metabolic disorders because of their smaller proportion of visceral adipose tissue [25]. In other words, larger waist circumference appears to be a stronger risk factor than BMI for metabolic syndrome [18]. Our finding of a strong correlation between waist circumference and thyroid nodule risk may therefore reflect the wellestablished correlation between metabolic syndrome and thyroid nodule risk $[2,4,8,9,19]$. Indeed, several of those previous studies have reported correlations between central obesity and thyroid nodule risk $[4,8,9]$. Central obesity lies at the core of metabolic syndrome [22], so it may not be surprising that our results show central obesity to be more closely associated with thyroid nodules than overweight and general obesity.

In our association analyses, we took into account age, gender, TSH and UIC as potential confounders. Thyroid nodules are known to be more prevalent in women [24] and older individuals [2-9], while waist circumference tends to larger in males and in the elderly. Thyroid nodule formation has been associated with TSH [9] and UIC $[10,11]$, and TSH has been associated with waist circumference [28]. Our observation that the increased risk of thyroid nodules was markedly attenuated after adjustment for these potential confounders suggests that these covariates also contribute to overall risk. Subgroup analyses showed that central obesity was significantly and independently associated with higher risk of thyroid nodules in nearly all subgroups, while BMI $\geq 24 \mathrm{~kg} / \mathrm{m}^{2}$ significantly correlated with increased risk of thyroid nodules only in women. This provides further evidence that, overall, central obesity is more strongly associated with risk of thyroid nodules than overweight and general obesity. The present study shows no evidence that gender, age, TSH, or UIC affects the observed relationship between risk of nodules and either $\mathrm{BMI} \geq 24 \mathrm{~kg} / \mathrm{m}^{2}$ or central obesity. Certainly, according to American Diabetes Association definition for overweight $\left(\geq 23 \mathrm{~kg} / \mathrm{m}^{2}\right)$ and obesity $\left(\geq 25 \mathrm{~kg} / \mathrm{m}^{2}\right)$ for Asians [24], higher BMI was also significantly associated with higher thyroid nodule risk among individuals with TSH $>4.2 \mathrm{mIU} / \mathrm{L}$, and TSH played an interactive role in the association between BMI and TNs, which might deserve further researches.

We found central obesity to be significantly related to higher thyroid nodule risk in men but not in women. While further work is needed to confirm that this is not merely a sample size effect, we suggest that it may reflect sex differences in the proportion of abdominal fat components. Women tend to have larger stores of subcutaneous fat than visceral fat, while men tend to have more visceral fat than subcutaneous fat for any given waist circumference $[25,26]$. This implies that increasing waist circumference represents, in men, primarily accumulation of visceral fat. Obese individuals with greater proportion of subcutaneous fat than visceral fat are at lower risk of metabolic syndrome than those with more visceral than subcutaneous fat [25]. These findings, when taken together with our present results, suggest that waist circumference-associated visceral fat may play a key role in the development of thyroid nodules.

These considerations may point to a key role of insulin resistance in formation of thyroid nodules. Visceral fat is the strongest predictor of insulin resistance [22, 25], which is a central contributor to metabolic syndrome [22]. One study in Italy found that while waist circumference was significantly associated with the presence of thyroid nodules, this association was no longer significant after adjusting for insulin resistance [19]. These results suggest that insulin resistance may be associated with thyroid nodule formation more strongly than even waist circumference. Indeed, our previous study of a large population suggested that insulin resistance is associated with the distribution, construction, and density of blood vessels in thyroid nodules [29]. Differences in such vascularization may help determine nodule growth and progression. It is possible that insulin resistance may cause changes in proliferative pathways activated directly by insulin or insulin-like growth factor-1 (IGF-1), which helps regulate thyroid gene expression and may be important in thyrocyte proliferation and differentiation [4, 30, 31]. Previous studies and the present work argue for focusing future research on the potential role of waist circumference-associated insulin resistance in the formation of thyroid nodules. The available evidence further suggests that effective diagnosis and treatment of insulin resistance may help prevent such nodules.

The present study extends previous work on associations of thyroid nodules with BMI or waist circumference to the case of a population with more than adequate iodine intake $(\mathrm{UIC}=239 \mu \mathrm{g} / \mathrm{L})$. In addition, our study was able to show that waist circumference was associated with thyroid nodules independently of TSH and UIC. These two thyroid nodule risk factors are usually ignored as potential confounders in the literature. Finally, our study systematically compared two adiposity measures, whereas most previous studies have focused on one or the other. 
Nevertheless, the results of the present work should be interpreted with caution in light of several limitations. First, the cross-sectional study design does not allow us to establish causal links between obesity measures and thyroid nodules. Second, although the multivariate model adjusted for as many confounders as possible, we did not control for other components of metabolic syndrome, including hyperglycemia, hypertension and dyslipidemia. This reflects the fact that the original purpose of our study was to investigate relationships between iodine nutrition and thyroid diseases, so we did not collect information about history of hypertension, diabetes or dyslipidemia. Third, we did not examine whether the relationship of thyroid nodule risk to BMI or waist circumference depends on the specific nodule subtype.

\section{Conclusions}

In this community-based Chinese population showing more than adequate iodine intake, waist circumference was consistently and more strongly associated than BMI with higher risk of thyroid nodules. These results suggest that waist circumference may be the better indicator of thyroid nodule risk. Maintaining normal waist circumference may help prevent thyroid nodules, particularly in men.

\section{Additional files}

Additional file 1: Table S1. Analysis of associations of thyroid nodules with different BMI cut-offs. (DOCX 19 kb)

Additional file 2: Table S2. Associations of thyroid nodules with different BMI cut-offs in subgroups of subjects stratified by gender, age, TSH or UIC. (DOCX $16 \mathrm{~kb})$

\section{Abbreviations}

ADA: American Diabetes Association; BMl: body mass index; Cl: Confidence interval; DBP: Diastolic blood pressure; IGF-1: Insulin-like growth factor-1; OR: Odds ratio; SBP: Systolic blood pressure; TgAb: Thyroglobulin antibodies; TPOAb: Thyroid peroxidase antibodies; TSH: Thyroid-stimulating hormone; UIC: Urine iodine concentration; WC: Waist circumference

\section{Acknowledgements}

\section{Not applicable}

\section{Funding}

Design and data collection were supported by the International Cooperation Foundation of the Ministry of Health of the People's Republic of China (2009); The development of the analytical methods and software used in this work was supported by the Foundation of Jiangsu Subei People's Hospital (yzucms201204), and writing the manuscript was supported in part by the Key Research and Development Project of Jiangsu Province (BE2015723)

\section{Availability of data and materials}

The datasets used and/or analyzed during the current study are available from the corresponding author on reasonable request.

\section{Authors' contributions}

WT developed the research questionnaire and wrote the protocol for this study. CL was responsible for the original study design and data collection together with the other authors. BS and ZZ analysed the data; BS and $Y L$ interpreted the results; $\mathrm{BS}, \mathrm{JT}$ and $\mathrm{ZZ}$ wrote the article and the other authors revised it critically for important intellectual content. All authors agreed to take responsibility for the integrity of the data and the accuracy of the data analysis. All authors have approved the final version of the manuscript.

\section{Ethics approval and consent to participate}

This study was conducted in accordance with the Declaration of Helsinki and approved by the medical ethics committee of China Medical University (serial number: IRB [2008]34). Written informed consent was obtained from all participants.

\section{Consent for publication}

Not applicable.

Competing interests

The authors declare that they have no competing interests.

\section{Publisher's Note}

Springer Nature remains neutral with regard to jurisdictional claims in published maps and institutional affiliations.

\section{Author details}

${ }^{1}$ Department of Endocrinology, The Second Affiliated Hospital of Nanjing Medical University, 125 Jiangjiayuan Road, Nanjing 211166, China. ${ }^{2}$ Department of Endocrinology, Clinical Medical College, Yangzhou University, 98 Nantong West Road, Yangzhou 225001, China. ${ }^{3}$ Department of Gerontology, Huai'an First People's Hospital, Nanjing Medical University, 6 Beijing West Road, Huai'an 223300, China. ${ }^{4}$ Department of Endocrinology, Second Hospital of Shanxi Medical University, 382 Wuyi Road, Taiyuan 030001, China. ${ }^{5}$ Department of Endocrinology and Metabolism, The First Hospital of China Medical University, 155 Nanjing Road, Shenyang 110001, China. ${ }^{6}$ Endocrine and Diabetes Center, Affiliated Hospital of Integrated Traditional Chinese and Western Medicine, Nanjing University of Chinese Medicine, 8 Huadian East Road, Nanjing 210028, China.

Received: 10 August 2017 Accepted: 19 January 2018

Published online: 27 January 2018

References

1. Burman KD, Wartofsky L. CLINICAL PRACTICE. Thyroid nodules. N Engl J Med. 2015;373(24):2347-56.

2. Guo H, Sun M, He W, Chen H, Li W, Tang J, Tang W, Lu J, Bi Y, Ning G, et al. The prevalence of thyroid nodules and its relationship with metabolic parameters in a Chinese community-based population aged over 40 years. Endocrine. 2014:45(2):230-5.

3. Jiang $H$, Tian $Y$, Yan W, Kong $Y$, Wang $H$, Wang A, Dou J, Liang P, Mu Y. The prevalence of thyroid nodules and an analysis of related lifestyle factors in Beijing communities. Int J Environ Res Public Health. 2016;13(4):442.

4. Feng S, Zhang Z, Xu S, Mao X, Feng Y, Zhu Y, Liu C. The prevalence of thyroid nodules and their association with metabolic syndrome risk factors in a moderate iodine intake area. Metab Syndr Relat Disord. 2017;15(2):93-7.

5. Xu W, Chen Z, Li N, Liu H, Huo L, Huang Y, Jin X, Deng J, Zhu S, Zhang S, et al. Relationship of anthropometric measurements to thyroid nodules in a Chinese population. BMJ Open. 2015;5(12):e008452.

6. Kim JY, Jung EJ, Park ST, Jeong SH, Jeong CY, Ju YT, Lee YJ, Hong SC, Choi SK, Ha WS. Body size and thyroid nodules in healthy Korean population. $J$ Korean Surg Soc. 2012;82(1):13-7

7. Sharen G, Zhang B, Zhao R, Sun J, Gai X, Lou H. Retrospective Epidemiological study of thyroid nodules by ultrasound in asymptomatic subjects. Chin Med J. 2014;127(9):1661-5.

8. Yin J, Wang C, Shao Q, Qu D, Song Z, Shan P, Zhang T, Xu J, Liang Q, Zhang $S$, et al. Relationship between the prevalence of thyroid nodules and metabolic syndrome in the iodine-adequate area of Hangzhou, China: a cross-sectional and cohort study. Int J Endocrinol. 2014;2014:675796.

9. Shin J, Kim MH, Yoon KH, Kang Ml, Cha BY, Lim DJ. Relationship between metabolic syndrome and thyroid nodules in healthy Koreans. Korean J Intern Med. 2016;31(1):98-105.

10. Chen Z, Xu W, Huang Y, Jin X, Deng J, Zhu S, Liu H, Zhang S, Yu Y. Associations of noniodized salt and thyroid nodule among the Chinese population: a large cross-sectional study. Am J Clin Nutr. 2013;98(3):684-92.

11. Shan Z, Chen L, Lian X, Liu C, Shi B, Shi L, Tong N, Wang S, Weng J, Zhao J, et al. lodine status and prevalence of thyroid disorders after introduction of 
mandatory universal salt iodization for 16 years in China: a cross-sectional study in 10 cities. Thyroid. 2016;26(8):1125-30.

12. Cappelli C, Pirola I, Mittempergher F, De Martino E, Casella C, Agosti B, Nascimbeni R, Formenti A, Rosei EA, Castellano M. Morbid obesity in women is associated to a lower prevalence of thyroid nodules. Obes Surg. 2012;22(3):460-4.

13. Zheng $L$, Yan W, Kong Y, Liang P, Mu Y. An epidemiological study of risk factors of thyroid nodule and goiter in Chinese women. Int J Environ Res Public Health. 2015;12(9):11608-20.

14. Sousa PA, Vaisman M, Carneiro JR, Guimarães L, Freitas H, Pinheiro MF, Liechocki S, Monteiro CM, Teixeira PF. Prevalence of goiter and thyroid nodular disease in patients with class III obesity. Arq Bras Endocrinol Metabol. 2013;57(2):120-5.

15. Chen H, Zhang H, Tang W, Xi Q, Liu X, Duan Y, Liu C. Thyroid function and morphology in overweight and obese children and adolescents in a Chinese population. J Pediatr Endocrinol Metab. 2013;26(5-6):489-96.

16. Lo K, Wong M, Khalechelvam P, Tam W. Waist-to-height ratio, body mass index and waist circumference for screening paediatric cardio-metabolic risk factors: a meta-analysis. Obes Rev. 2016;17(12):1258-75.

17. Kramer H, Gutiérrez OM, Judd SE, Muntner P, Warnock DG, Tanner RM, Panwar B, Shoham DA, McClellan W. Waist circumference, body mass index, and ESRD in the REGARDS (reasons for geographic and racial differences in stroke) study. Am J Kidney Dis. 2016;67(1):62-9.

18. Zhang P, Wang R, Gao C, Jiang L, Lv X, Song Y, Li B. Prevalence of central obesity among adults with normal BMI and its association with metabolic diseases in Northeast China. PLoS One. 2016;11(7):e0160402.

19. Ayturk S, Gursoy A, Kut A, Anil C, Nar A, Tutuncu NB. Metabolic syndrome and its components are associated with increased thyroid volume and nodule prevalence in a mild-to-moderate iodine-deficient area. Eur J Endocrinol. 2009;161(4):599-605.

20. Yan YR, Liu Y, Huang H, Lv QG, Gao XL, Jiang J, Tong NW. lodine nutrition and thyroid diseases in Chengdu, China: an epidemiological study. QJM. 2015;108(5):379-85.

21. Cooper DS, Doherty GM, Haugen BR, Hauger BR, Kloos RT, Lee SL, Mandel SJ, Mazzaferri EL, Mclver B, Pacini F, et al. Revised American Thyroid Association management guidelines for patients with thyroid nodules and differentiated thyroid cancer. Thyroid. 2009:19(11):1167-214.

22. Alberti KG, Zimmet P, Shaw J. The metabolic syndrome-a new worldwide definition. Lancet. 2005;366(9491):1059-62.

23. Chen W. Consensus statement of the Chinese medical and nutritional experts on management for overweight/obesity in China (2016). Chin J Diabetes Mellitus. 2016;8(9):525-40.

24. American Diabetes Association. Standards of medical Care in Diabetes-2017 abridged for primary care providers. Clin Diabetes. 2017;35(1):5-26.

25. Power ML, Schulkin J. Sex differences in fat storage, fat metabolism, and the health risks from obesity: possible evolutionary origins. Br J Nutr. 2008;99(5):931-40.

26. Lemieux S, Prud'homme D, Bouchard C, Tremblay A, Després JP. Sex differences in the relation of visceral adipose tissue accumulation to total body fatness. Am J Clin Nutr. 1993;58(4):463-7.

27. Janssen I, Katzmarzyk PT, Ross R. Waist circumference and not body mass index explains obesity-related health risk. Am J Clin Nutr. 2004;79(3):379-84.

28. Mamtani M, Kulkarni H, Dyer TD, Almasy L, Mahaney MC, Duggirala R, Comuzzie AG, Samollow PB, Blangero J, Curran JE. Increased waist circumference is independently associated with hypothyroidism in Mexican Americans: replicative evidence from two large, population-based studies. BMC Endocr Disord. 2014;14:46

29. Wang K, Yang Y, Wu Y, Chen J, Zhang D, Mao X, Wu X, Long X, Liu C. The association between insulin resistance and vascularization of thyroid nodules. J Clin Endocrinol Metab. 2015:100(1):184-92.

30. Marcello MA, Cunha LL, Batista FA, Ward LS. Obesity and thyroid cancer. Endocr Relat Cancer. 2014:21(5):T255-71.

31. Pappa T, Alevizaki M. Obesity and thyroid cancer: a clinical update. Thyroid. 2014:24(2):190-9.

\section{Submit your next manuscript to BioMed Central and we will help you at every step:}

- We accept pre-submission inquiries

- Our selector tool helps you to find the most relevant journal

- We provide round the clock customer support

- Convenient online submission

- Thorough peer review

- Inclusion in PubMed and all major indexing services

- Maximum visibility for your research

Submit your manuscript at www.biomedcentral.com/submit
Biomed Central 